\title{
WEATHER CONDITION ASSOCIATED WITH INFLUENCE OF THE ANTARCTIC OZONE HOLE OVER SOUTH OF BRAZIL ON OCTOBER 21 th 2011
}

\author{
Lucas Vaz Peres ${ }^{1 *}$, Andre Passaglia Shuch ${ }^{1}$, Vagner Anabor ${ }^{1}$, \\ Damaris Kirsch Pinheiro', Nelson Jorge Shuch², Neusa Maria Paes Leme ${ }^{3}$
}

\author{
${ }^{1}$ Universidade Federal de Santa Maria - UFSM, Av. Roraima N¹000, Camobi, CEP: 97105-900, Santa Maria, Brazil \\ ${ }^{2}$ Centro Regional Sul de Pesquisas Espaciais, Instituto Nacional de Pesquisas Espaciais, Campus Universitário, \\ CEP 97105-970, Santa Maria, Brazil \\ ${ }^{3}$ Centro Regional do Nordeste, Instituto Nacional de Pesquisas Espaciais, Rua Carlos Serrano, № 2073, \\ Lagoa Nova, CEP 59076-740, Natal, RN, Brazil \\ *e-mail: lucasvazperes@gmail.com
}

\begin{abstract}
An analysis of the weather condition is presented in this work, associated with the occurrence of the Influence of Antarctic Ozone Hole over southern Brazil on October 21 $1^{\text {th }}$ 2011. In this date, there was a drop in ozone content of the $4.65 \%$ in relation to climatological average of the October at the data obtained through the Brewer Spectrophotometer MKIII 167 installed in South Space Observatory - OES/CRS/INPE - MCTI and instrument of satellite OMI of the NASA. The origin of the stratospheric polar air mass poor in ozone has been proven by the analysis of potential vorticity maps, retroactive trajectories and satellite images of the ozone content. The tropospheric weather condition in the South of Brazil, associated with the event was the occurrence of a wide area of atmospheric stability, without significant clouds, associated with the subtropical jet stream away from the Atlantic Ocean, superimposed by a wide area of the subsidence movement and occurrence of the an intense high-pressure post-front system.
\end{abstract}

Keywords: Stratospheric Ozone, Tropospheric Weather Condition

\section{Introduction}

The passage of air masses originating from the Antarctic ozone hole (Farman et al., 1985) on medium latitudes was first observed on the South of Brazil $\left(29.4^{\circ} \mathrm{S} ; 53.8^{\circ} \mathrm{W}\right)$ by Kirchhoff et al. (1996), being this type of phenomenon called 'influence of the Antarctic ozone hole, which has been frequently observed over South America (Perez et al., 2000; Pinheiro et al., 2012).

Peres et al., 2012, observed that the event of the Influence of Antarctic Ozone Hole over southern Brazil on October $13^{\text {th }}, 2010$, occurred after the passage of a tropospheric frontal system.

This study aims to verify the weather condition of troposphere during the occurrence of of the Influence of Antarctic Ozone Hole over southern Brazil on October, $21^{\text {th }}, 2011$.

\section{Material and Methods}

Events of influence of the Antarctic ozone hole over the South of Brazil are identified through observation of falls below the limit climatological average less 1.5 standard deviation in total column ozone data obtained through the Brewer Spectrophotometer MKIII \#167 installed on South Space Observatory - OES/CRS/INPE - MCTI (29,4º S; 53,8 W; 488,7 m), in São Martinho da Serra and by the satellite instrument IMO of the NASA, which are also used his images ozone content. In these days, the stratospheric origin of ozone-poor air masses is verified through the analysis of Potential Vorticity (Semane et al., 2006) over isentropic surface of $620 \mathrm{~K}$ potential temperature, using daily parameters provided by NCEP/NCAR reanalysis, for the purpose of checking the dynamic pattern of the stratosphere. Retroactive trajectories of air masses were made by HYSPLIT model of the NOAA confirms the 
polar source of ozone-poor air mass and your passing by the polar region. The identification of the tropospheric weather condition is carried out through the analysis of wind fields at $250 \mathrm{hPa}$ and Vertical speed Omega in $500 \mathrm{hPa}$, sea level pressure and thickness between 1000 and $500 \mathrm{hPa}$ and GOES 12 satellite images enhanced infrared, in order to identify any connection between the stratosphere and the troposphere during the occurrence of this event.

\section{Results}

The day October $21^{\text {th }}, 2011$, showed the value of total ozone column of 278.7 DU representing a decrease of $4.7 \%$ compared to the climatological average for the month of

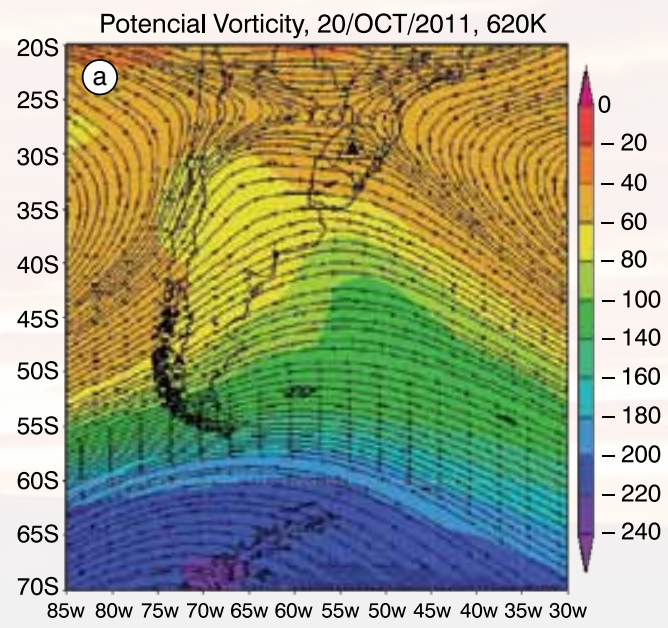

NOAA HYSPLIT MODEL

Backward trajectory ending at 0000 UTC 22 Oct 11 CDC1 Meteorological Data

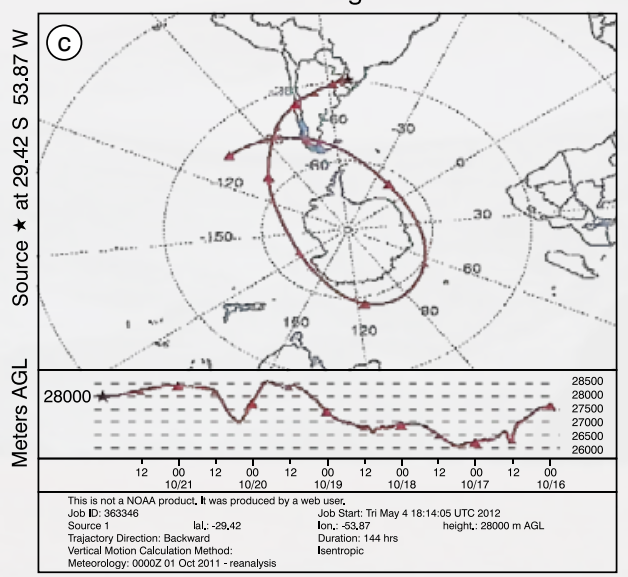

October which is $292.3 \pm 9.9 \mathrm{DU}$. The stratospheric analysis shows, from the isentropic analysis, an increase of the values of absolute potential vorticity in the $620 \mathrm{~K}$ potential temperature level of day 21 (a) to day 22 (b) of the October, 2011 , indicating that the origin of ozone-poor air mass that arrived southern Brazil was polar. Backward trajectory of air masses (c) and the satellite image IMO (d) complement the analysis, confirming the polar origin of the air mass and the existence of a connection between the polar region, where acted the Antarctic Ozone Hole and Southern Brazil, seen in Figure 1.

The tropospheric weather condition, seen in Figure 2, shows that over South of Brazil, acted a wide area of atmospheric stability, with the displacement of the
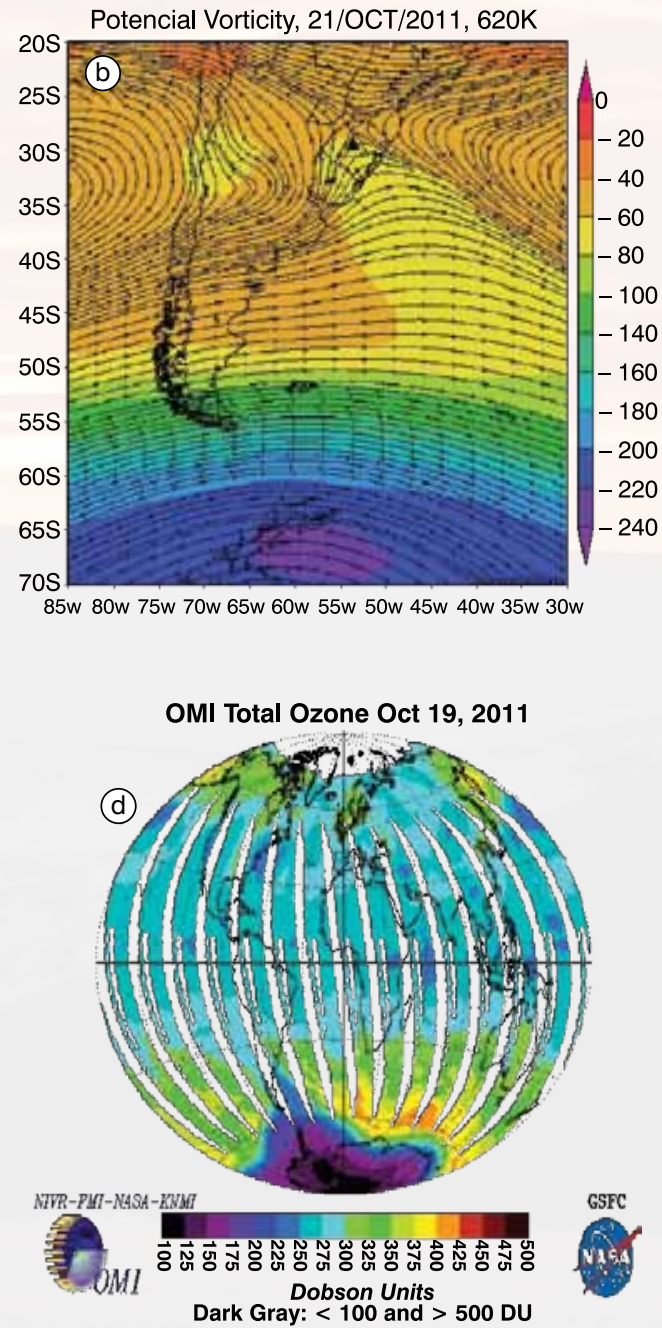

Figure 1. Potential Vorticity and Wind at $620 \mathrm{~K}$ level for $20^{\text {th }}(\mathrm{a})$ and $21^{\text {th }}$ (b) of October, 2011. Air mass backward trajectory (c) and OMl image (d) for $22^{\text {th }}$ and $19^{\text {th }}$, respectively. 
subtropical jet stream toward the Atlantic Ocean, and the performance of their region of polar input and center of positive values of Omega in the wind field in $250 \mathrm{hPa}$ and Vertical speed Omega in $500 \mathrm{hPa}$ over South of Brazil in October $20^{\text {Th }}, 2011$ (a), characteristic by subsidence and intrusion of stratospheric air into the troposphere.

The performance of a high pressure post frontal system in the field pressure at sea level and thickness between the levels of 1000 and $500 \mathrm{hPa}$ in October 21 (b), characteristic by the divergence of the air at low levels, inhibit cloudiness formation, as observed in the satellite image of the infrared highlighted of GOES 12 to 15 UTC in October 21 (c) 2011.

20/10/2011

Jet $250 \mathrm{mb}(\mathrm{m} / \mathrm{s})$ and Omega $500 \mathrm{mb}(\mathrm{m} / \mathrm{s})$

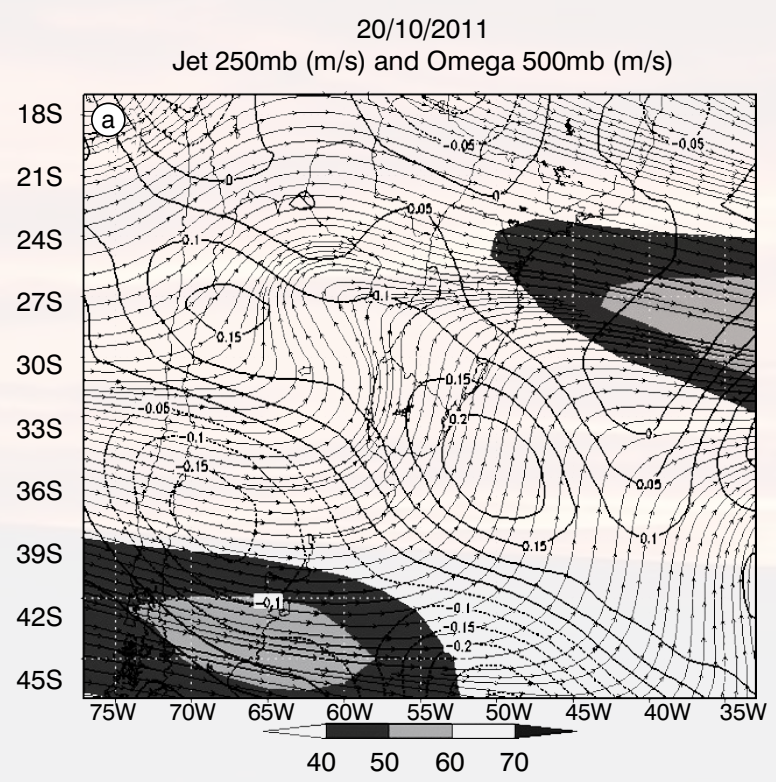

This pattern of atmospheric circulation, with the displacement of the subtropical jet stream from medium to low latitudes, may have aided in its southern sector, in stratospheric air intrusion into the troposphere and in the transport of ozone-poor air mass from Antarctic region to the South of Brazil, showing evidence of a connection between the stratosphere and the troposphere.

\section{Discussion}

Events of Influence of Antarctic Ozone Hole over middle latitudes is becoming more frequent (Kirchhoff et al., 1996;
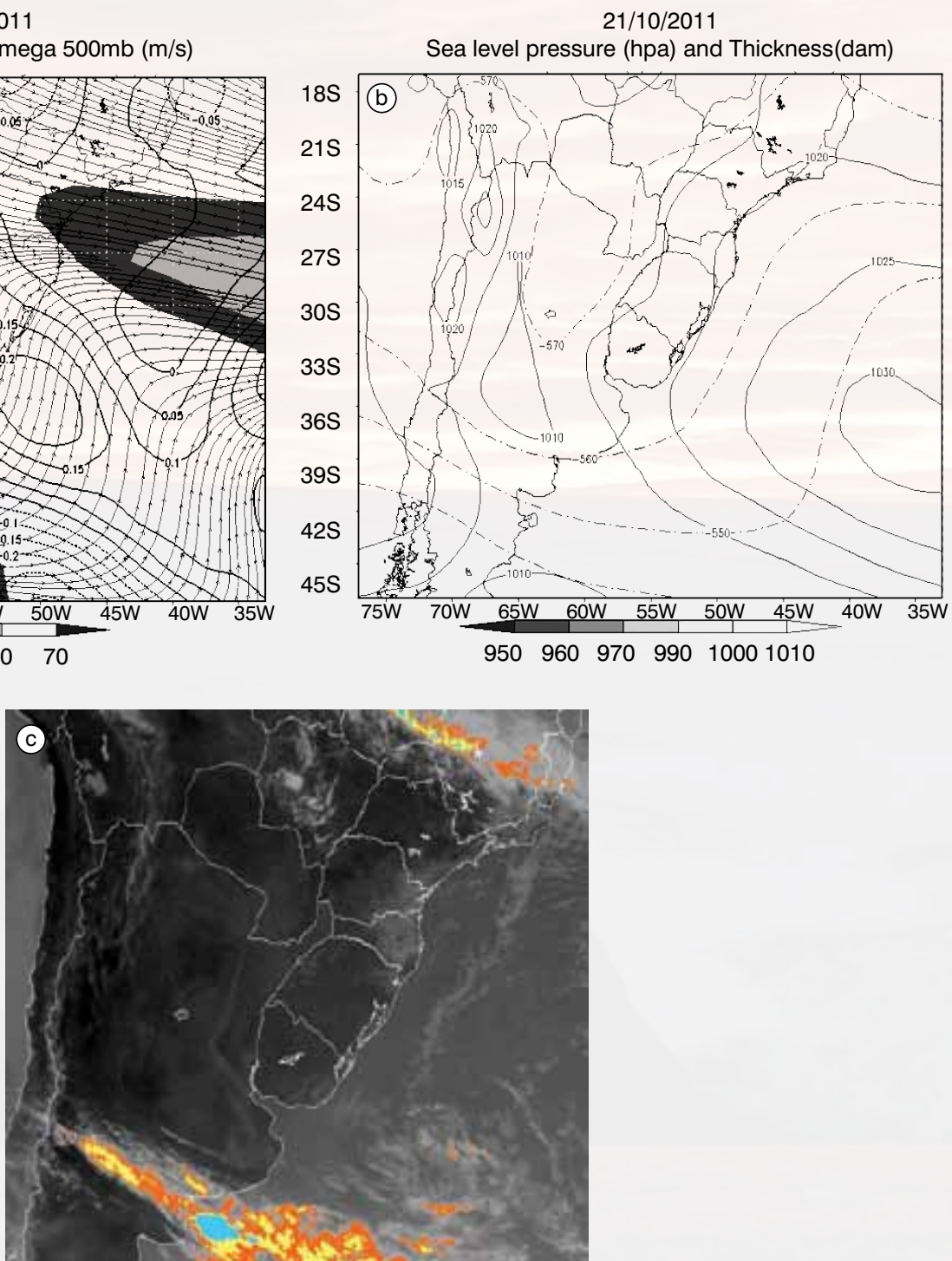

Figure 2. Field daily average at $250 \mathrm{hPa}$ level and Omega at $500 \mathrm{hPa}$ for October, 20th, 2011 (a), pressure at sea level and thickness between 1000 and 500 $\mathrm{hPa}(\mathrm{b})$, and enhance GOES 12 image satellite at 15:00 (c) for October, $21^{\text {th }}, 2011$. 
Perez et al., 2000; Pinheiro et al., 2012, Peres et al., 2012), as well as the identification of the existence of a connection between the transport of air masses in the stratosphere and the troposphere weather condition, mainly by the performance of the tropospheric jet stream, where its displacement influence the vertical distribution of ozone content (Bukin et al. 2011) and causes intrusion of stratospheric air into the troposphere (Stohl et al., 2003). Moreover, on the South of Brazil, similar to the way the present study, this type of event has occurred after the passage of a frontal system (Peres et al., 2012).

\section{Conclusion}

The occurrence of the event of influence of the Antarctic ozone hole over South of Brazil in October $21^{\text {th }}, 2011$ was confirmed by the drop in ozone content that reached $4.7 \%$ relative the climatological average for the month of October and stratospheric isentropic analysis of potential vorticity, backward trajectory and ozone content of the satellite image showed that the ozone-poor air mass that arrived at South of Brazil was of polar origin at the Antarctic ozone hole.

The tropospheric weather condition shows that this event ocurred in conjunction with a wide area of atmospheric stability over South of Brazil associated with a post front condition, without significant cloud cover, occasioned by shift at the Atlantic Ocean of the subtropical jet stream and acting of a post frontal high-pressure system, characterized by the subsidence of air masses, inhibition of formation of cloud cover which may have favored the transport of stratospheric ozone-poor air mass.

\section{Acknowledgements}

This work integrates the National Institute of Science and Technology Antarctic Environmental Research (INCTAPA) that receives scientific and financial support from the National Council for Research and Development (CNPq process: ${ }^{\circ}$ 574018/2008-5) and Carlos Chagas Research Support Foundation of the State of Rio de Janeiro (FAPERJ $n^{\circ}$ E-16/170.023/2008). The authors also acknowledge the support of the Brazilian Ministries of Science, Technology and Innovation (MCTI), of Environment (MMA) and Inter-Ministry Commission for Sea Resources (CIRM). Acknowledgements also to FAPEREGS/CAPES for fellowship, NASA/TOMS and NCEP/NCAR for the data, and NOAA for HYSPLIT model.

\section{References}

Bukin, O. A., Suan A, N., Pavlov, A. N., Stolyarchuk, S. Y., \& Shmirko, K. A. (2011). Effect that Jet Streams Have on the Vertical Ozone Distribution and Characteristics of Tropopause Inversion Layer, Izvestiya Atmospheric and Oceanic Physics, 47(5), 610-618. http://dx.doi.org/10.1134/S0001433811050021

Farman, J. C., Gardiner, B. G., \& Shanklin, J. D. (1985) Large losses of total ozone in Antarctica reveal seasonal CIOx/NOx interaction. Nature, 315, 207-210. http://dx.doi.org/10.1038/315207a0

Kirchhoff, V. W. J. H., Schuch, N. J., Pinheiro, D. K., \& Harris, J. M. (1996) Evidence for an ozone hole perturbation at $30^{\circ}$ south. Atmospheric Environment, 33(9), 1481-1488. http://dx.doi.org/10.1016/1352-2310(95)00362-2

Peres, L. V., Crespo, N. M., Silva, O. K., Hupfer, N., Anabor, V., Pinheiro, D. K. et al. (2012). Sinoptic weather system associate with influence of the Antartic Ozone Hole over South of Brazil at October, 13th, 2010. Annual Active Report 2011, 1, 30-33, 2012.

Perez, A., Crino, E., De Carcer, I. A., Jaque, F. (2000). Low-ozone events and three-dimensional transport at midlatitudes of South America during springs of 1996 and 1997. Journal of Geophysical Research: Atmospheres, 105(D4), 4553-4561. http://dx.doi.org/10.1029/1999JD901040

Pinheiro, D. K., Peres, L. V., Crespo, N. M., Schuch, N. J., \& Leme, N., P. (2012). Influence of the Antarctic ozone hole over South of Brazil in 2010 and 2011. Annual Active Report 2011, 1, 34-38

Semane, N., Bencherif, H., Morel, B., Hauchecorne, A., \& Diab, R. D. (2006) An unusual stratospheric ozone decrease in Southern Hemisphere subtropics linked to isentropic air-mass transport as observed over Irene $\left(25.5^{\circ} \mathrm{S}, 28.1^{\circ} \mathrm{E}\right)$ in midMay 2002. Atmospheric Chemistry and Physics, 6, 1927-1936. http://dx.doi.org/10.5194/acp-6-1927-2006

Stohl, A., Wernli, H., Bourqui, M., Forster, C., James, P., Liniger, M. A. et al. (2003). A new perspective of stratospheretroposphere exchange. Bulletin of the American Meteorological Society, 84, 1565-1573. http://dx.doi.org/10.1175/BAMS84-11-1565 